\section{CRYOSPHERIC SCIENCE}

Greenland feels the heat

Proc. Natl Acad. Sci. USA 116, 1934-1939 (2019).

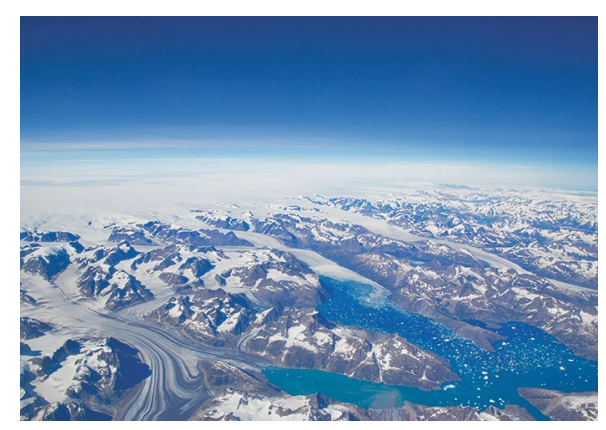

Credit: Elijah Lovkoff/Alamy Stock Photo

The warming of both the ocean and the atmosphere is causing loss of the Greenland Ice Sheet through surface melt and iceberg calving. How each of these contribute to the loss-rate and regional effects was investigated by Michael Bevis, of Ohio State University, and co-authors.

They combine remotely sensed data from the Gravity Recovery and Climate Experiment (GRACE) mission and the Greenland GPS Network with regional climate simulations. In 2003, the Greenland Ice sheet was losing $102 \mathrm{Gt}$ of ice per year. Over the following ten years this has accelerated progressively to $\sim 393 \mathrm{Gt}$ per year. While large losses were seen for the southeast and northwest, where there are numerous marine-terminating glaciers, the southwest - a smaller contributor and a region with few marine-terminating glaciers - saw the largest sustained acceleration.
This acceleration tracks the North Atlantic Oscillation, which in its negative phase increases summer warming and incoming radiation, whilst decreasing snowfall; resulting in increased surface melt and loss.

The acceleration and subsequent deceleration, in 2013-2014, is attributed to atmospheric forcing (air temperature and incoming radiation) - highlighting the potential of future loss from southwest Greenland.

https://doi.org/10.1038/s41558-019-0451-7

\section{BIODIVERSITY}

\section{Growth in destruction}

Nat. Eco. Evol. http://doi.org/c3fj (2019).

Land use by agriculture and forestry has direct ramifications for biodiversity and carbon storage. Population growth and socioeconomic development are fuelling growth in the demand for land-derived products. If we are to move away from destructive land-use practices, we need to understand the complex patterns of trade that link global production and consumption.

Alexandra Marques from Leiden University, The Netherlands, and the German Centre for Integrative Biodiversity Research, and co-authors use a combination of biophysical and economic models to analyse the global impacts of agricultural and forestry activities on avian diversity and carbon sequestration, taking account of international trade.

They find that, from 2000 to 2011, population and economic growth drove

\section{CLIMATE DISCOURSE}

\section{Idea coalitions in climate policy}

Global Environ. Chang. 55, 73-83 (2019).

The challenge of negotiating international environmental policy lies in incentivizing cooperation among diverse interests, and agreeing on a definition of the problem and the appropriate solutions. Understanding how the latter translates into country coalitions is crucial for understanding the Paris Agreement's design and future prospects.

Maria Jernnäs and Björn-Ola Linnér, of Linköping University, Sweden, use discursive analysis to identify storylines in 136 National Determined Contributions (NDCs) representing 164 parties to the Paris Agreement. NDCs, nearly universally, situate solutions to climate change in the context of liberal economics and natural resource management, while some also feature discussions of non-state climate action, climate change as a security threat, empowerment of the vulnerable and principles of equity. A very small minority discuss justice and system change. Shared storylines do not neatly overlap with existing geopolitical groupings, but geographical proximity and income groupings do coincide with calls for an adjustment of the current liberal order. The divergent storylines suggest there is clearly still work to be done in determining the extent of the societal transformation needed to meet global climate goals, and exactly what it means to increase ambition.

https://doi.org/10.1038/s41558-019-0450-8 increasing land-use impacts on bird diversity and carbon sequestration globally, despite a reduction in impact per unit of economic growth (GDP). Rearing cattle was the greatest driver of biodiversity loss, with oil-seed production impacts growing the fastest. Forestry had the largest impact on carbon sequestration, and also showed the greatest increase. Between a third and a quarter of biodiversity impacts in Central and Southern America and Africa were driven by consumption in other parts of the world. These findings suggest that sustainable land-use and preservation of carbon stocks requires recognition of trade-driven remote responsibility for environmental impacts.

https://doi.org/10.1038/s41558-019-0449-1

\section{CLIMATE GOVERNANCE}

\section{Drivers of transnational action}

Global Environ. Polit. 19, 99-122 (2019).

The Paris Agreement has amplified the significance of private, voluntary, marketbased initiatives in achieving global climate change commitments. However, these programs are less prevalent in the Global South, where incentives and capacity are weaker than industrialized countries. Understanding the limited uptake of private initiatives in developing countries has implications for the success and legitimacy of transnational governance approaches to global challenges.

Liliana Andonova, from the Graduate Institute of International and Development Studies, Geneva, and Yixian Sun, from Yale University, analyse project-level data from voluntary carbon offset programs (VCO) registered in developing countries as of 2016. They find that countries with more projects registered through the international Clean Development Mechanism and that receive more climate-directed foreign aid, are more likely to participate in VCO. In addition, domestic factors such as vulnerability (particularly in countries without the market power of emerging economies) and public policy supporting renewable technology, also determine VCO participation. The authors conclude that VCO participation in developing countries is driven by local concerns and priorities, but support from formal international institutions is needed to increase interest and build capacity. 